\title{
ANALISA MANAJEMEN STRATEGIK PT FONDACO JAYATAMA DALAM BERSAING
}

\author{
Mauren Astria \\ Program Studi Magister Manajemen Universitas Tarumanagara \\ maurenastria29@gmail.com \\ Eko Harry Susanto \\ Program Studi Magister Manajemen Universitas Tarumanagara
}

\begin{abstract}
:
To support the improvement of dental health in the community it is necessary to overcome them. The efforts of PT Fondaco on the fact encourage the founder to become one of the suppliers who support a variety of dental experts in the treatment by providing various medical purposes.The purpose of this research is to analyze the influence of external environment, and internal to competitiveness and analyze the competitive strategy of PT Fondaco Jayatama to improve competitiveness. The method used in this research is qualitative descriptive method by doing SWOT analysis (EFE and IFE matrix), IE matrix in matching stage, and QSPM analysis in desicion stage. The results of the EFE and IFE matrix analysis showed that Fondaco Jayatama can used all the opportunities and can overcomed threats from the rivalry. PT Fondaco Jayatama also has a good internal and can not be down by the external environment. PT Fondaco Jayatama was a strong competitors. The conclusion of this research is product development strategy is the best strategy to be apply in the organization.
\end{abstract}

Keywords : strategic management, product development strategy, market penetration, product development, SWOT analysis, IFE analysis, EFE analysis.

\section{PENDAHULUAN}

Kesehatan merupakan suatu aspek penting dan tidak dapat diremehkan begitu saja. Salah satu bagian dari tubuh yang sering diremehkan adalah kesehatan gigi, permasalahan yang berhubungan dengan kesehatan gigi sering dianggap remeh dan tidak jarang yang mengabaikannya. Kesehatan secara keseluruhan, kesejahteraan, pendidikan dan pengembangan anak, keluarga dan masyarakat dapat dipengaruhi oleh kesehatan gigi. Kurangnya ketersediaan dan keterjangkauan pelayanan kesehatan tidak hanya menghasilkan gangguan penyakit tetapi juga meningkatkan biaya pengobatan dan perawatan bila penyakitnya tersebut sudah menjadi parah. Permasalahan kesehatan gigi pada anak sering berlanjut sampai dewasa, mempengaruhi produktivitas dan kualitas hidup. Usaha pemerintah dalam membangun kesehatan tentunya membutuhkan para ahli yang dapat memberikan penjelasan mengenai pentingnya menjaga kesehatan gigi dan cara mengatasi penyakit gigi. Untuk mendukung peningkatan kesehatan gigi di masyarakat maka diperlukan berbagai penyuluhan dan pengobatan untuk mengatasinya.

Upaya PT Fondaco atas fakta yang ada mendorong founder untuk menjadi salah satu supplier yang mendukung berbagai ahli gigi dalam melakukan pengobatan dengan menyediakan berbagai keperluan pengobatan. Dengan memanfaatkan peluang yang tersedia, maka PT Fondaco dapat terus berkembang sampai saat ini dan memiliki posisi khusus bagi customernya. 
Pada penelitian kali ini, penulis memutuskan beberapa rumusan masalah yaitu, strategi apa yang telah dilakukan oleh PT Fondaco Jayatama dalam bersaing dan langkah langkah apa yang dilakukan untuk menjalankan strategi bersaing tersebut.

Tujuan dari penelitian yang dilakukan adalah menganalisis pengaruh lingkungan eksternal, dan internal terhadap daya saing dan menganalisis strategi bersaing PT Fondaco Jayatama untuk meningkatkan daya saing.

\section{TINJAUAN PUSTAKA}

Konsep Manajemen Strategi, manajemen strategi merupakan sekumpulan keputusan manajerial dan aksi pengambilan keputusan jangka panjang didalam perusahaan. Formulasi strategi merupakan pengembangan perencanaan jangka panjang untuk manajemen yang efektif melalui analisis lingkungan (internal dan eksternal). Implementasi strategi adalah sebuah proses yang mana strategi dan kebijakan diarahkan kedalam tindakan melalui pengembangan program, anggaran, dan prosedur. Hasil evaluasi strategi akan bermanfaat dan menjadi masukan dalam proses manajemen strategi perusahaan selanjutnya.

Strategi Bersaing dan Keunggulan Bersaing. Strategi bersaing merupakan perencanaan yang dirancang oleh perusahaan untuk mencapai keunggulan kompetitif dalam bersaing untuk berhadapan dengan kompetitornya dan memenangkan persaingan yang ada. Sedangkan keunggulan bersaing sendiri pada dasarnya tumbuh dari nilai-nilai atau manfaat yang diciptakan oleh perusahaan bagi para pembelinya.

Analisis Lingkungan Eksternal dan Internal, Faktor-faktor lingkungan eksternal meliputi analisis faktor-faktor politik, ekonomi, sosial, dan teknologi (PEST), analisis lingkungan industri industry dengan mengunakan alat analisis model lima kekuatan (five forces model) yang dikembangkan oleh Porter. Sedangkan lingkungan internal merupakan lingkungan yang berada di dalam perusahaan dan secara normal memiliki implikasi yang langsung dan khusus pada perusahaan. Faktor internal merupakan kemampuan dasar perusahaan, keterbatasan dan juga ciri khas yang dimiliki perusahaan.

Analisis SWOT, Analisis SWOT (Strength, Weakness, Opportunity and Threat) adalah metode perencanaan strategis yang digunakan untuk mengevaluasi kekuatan, kelemahan, peluang, dan ancaman dalam suatu proyek atau suatu spekulasi bisnis.

Matriks IFE, EFE, IE, dan SWOT, Matriks Internal Factor Evaluation (IFE) digunakan untuk mengetahui faktor-faktor internal perusahaan berkaitan dengan kekuatan dan kelemahan yang dianggap penting, khususnya dalam bidang fungsional. Matriks External Factor Evaluation (EFE) merupakan sebuah daftar yang membuat serangkaian faktor strategis eksternal yang terdiri atas peluang dan ancaman. Sedangkan matriks Internal External Factor Evaluation (IE) merupakan gabungan kedua matriks IFE dan EFE menghasilkan matriks internal-eksternal dengan berisikan sembilan macam sel yang memperlihatkan kombinasi total nilai terboboti dari matriks-matriks IFE dan EFE. Tujuan penggunaan matriks ini adalah untuk memperoleh strategi bisnis di tingkat corporate yang lebih detail.

\section{METODOLOGI PENELITIAN}

Pengumpulan data pada tesis ini menggunakan metode deskriptif kualitatif, dimana dilakukan pengamatan secara langsung melalui tindakan observasi lingkungan dengan melakukan pengamatan terhadap perusahaan mengenai persaingan yang terjadi dan berdasarkan dengan fakta-fakta yang ada disertai interpretasi keadaan usaha yang sebenarnya. Teknik pengumpulan data dengan mengumpulkan data sekunder yang ada dan jug apenelitian lapangan secara langsung.

Metode penelitian yang penulis gunakan adalah analisis lingkungan perusahaan (eksternal dan internal), analisis SWOT, matriks EFE, IFE, IE, dan analisis Organisasi dan Sumber Daya Manusia yang ada di perusahaan. 


\section{HASIL DAN PEMBAHASAN}

- Analisis SWOT

○ Matriks EFE ( External Factor Evaluation )

\begin{tabular}{|c|c|c|c|c|}
\hline \multicolumn{2}{|c|}{ Faktor Eksternal } & Bobot & Peringkat & Nilai \\
\hline \multicolumn{5}{|c|}{ Peluang (Opportunities) } \\
\hline 1 & $\begin{array}{l}\text { Market size yang besar, menjangkau } \\
\text { seluruh Indonesia }\end{array}$ & 0,16 & 4 & 0,64 \\
\hline 2 & $\begin{array}{l}\text { Mulai adanya kesadaran dari konsumen } \\
\text { bahwa kualitas yang baik itu penting. }\end{array}$ & 0,05 & 1 & 0,05 \\
\hline 3 & $\begin{array}{l}\text { Adanya pertumbuhan ekonomi } \\
\text { masyarakat Indonesia }\end{array}$ & 0,08 & 2 & 0,16 \\
\hline 4 & $\begin{array}{l}\text { Pesaing di industri yang sama masih } \\
\text { terbilang sedikit. }\end{array}$ & 0,07 & 2 & 0,14 \\
\hline 5 & $\begin{array}{l}\text { Adanya keunggulan karena sudah } \\
\text { dikenal bahkan sampai ke luar negri, } \\
\text { sehingga mudah untuk memanggil } \\
\text { pembicara yang berasal dari luar } \\
\text { Indonesia. }\end{array}$ & 0,09 & 3 & 0,27 \\
\hline \multicolumn{5}{|c|}{$\begin{array}{l}\text { Ancaman (Threats) } \\
\end{array}$} \\
\hline 1 & $\begin{array}{l}\text { Adanya pesaing yang menjual produk } \\
\text { yang sama dengan harga yang lebih } \\
\text { murah. }\end{array}$ & 0,16 & 4 & 0,64 \\
\hline 2 & Terjadi persaingan harga yang ketat. & 0,16 & 4 & 0,64 \\
\hline 3 & $\begin{array}{l}\text { Produk yang dijual termasuk untuk } \\
\text { kalangan menengah keatas. }\end{array}$ & 0,08 & 2 & 0,16 \\
\hline 4 & $\begin{array}{l}\text { Kurangnya kesadaran dari konsumen } \\
\text { bahwa lebih nyaman } r \text { untuk } \\
\text { menggunakan produk dengan kualitas } \\
\text { yang baik. }\end{array}$ & 0,05 & 1 & 0,05 \\
\hline 5 & $\begin{array}{l}\text { Ada beberapa calon pembeli yang sudah } \\
\text { terdoktrin bahwa yang dijual oleh PT } \\
\text { Fondaco terlampau mahal. }\end{array}$ & 0,10 & 3 & 0,30 \\
\hline \multicolumn{2}{|r|}{ Total } & 1 & & 3,05 \\
\hline
\end{tabular}

Hasil :

Total perkalian antara bobot dengan peringkat yang menunjukkan angka $>3$, yaitu 3,05 dapat diartikan bahwa perusahaan mampu memanfaatkan peluang yang ada dan dapat mengatasi ancaman serta PT Fondaco Jayatama memiliki kemampuan untuk meraih kesempatan yang ada. 
○ Matriks IFE ( Internal Factor Evaluation )

\begin{tabular}{|c|c|c|c|c|}
\hline \multicolumn{2}{|c|}{ Faktor Internal } & Bobot & Rating & Nilai \\
\hline \multicolumn{5}{|c|}{ Kekuatan (Strengths) } \\
\hline 1 & $\begin{array}{l}\text { PT Fondaco menjadi distributor tunggal untuk } \\
\text { banyak brand yang berasal dari benua Eropa } \\
\text { ataupun Amerika. }\end{array}$ & 0,12 & 4 & 0,48 \\
\hline 2 & $\begin{array}{l}\text { Memberikan berbagai macam acara edukasi dan } \\
\text { seminar khusus untuk para customernya dengan } \\
\text { menghadirkan pembicara yang terkenal dan } \\
\text { memang ahli. }\end{array}$ & 0,08 & 4 & 0,32 \\
\hline 3 & $\begin{array}{l}\text { Adanya service after purchased dan traning } \\
\text { yang diberikan oleh PT Fondaco kepada } \\
\text { konsumen yang membeli unit-unit tertentu yang } \\
\text { membutuhkan pelatihan. }\end{array}$ & 0,08 & 4 & 0,32 \\
\hline 4 & $\begin{array}{l}\text { Pengantaran pesanan dilakukan } 2 \text { kali dalam } \\
\text { sehari atau bahkan lebih bila ada pesanan yang } \\
\text { urgent (dengan dilakukan pengecekan } \\
\text { ketersediaan kurir dahulu) dan pengiriman gratis } \\
\text { untuk beberapa wilayah di jakarta yang telah } \\
\text { diatur sebelumnya. }\end{array}$ & 0,04 & 3 & 0,12 \\
\hline 5 & $\begin{array}{l}\text { Untuk wilayah diluar batas pengantaran kurir, } \\
\text { PT Fondaco telah bekerjasama dengan salah satu } \\
\text { agensi pengiriman yaitu } 21 \text { Express. }\end{array}$ & 0,04 & 3 & 0,12 \\
\hline 6 & $\begin{array}{l}\text { Adanya kerjasama yang dilakukan dengan } \\
\text { beberapa fakultas kedokteran gigi di Universitas } \\
\text { Trisakti dan Universitas Indonesia. }\end{array}$ & 0,08 & 4 & 0,32 \\
\hline 7 & Produk yang dijual sudah diakui kualitasnya. & 0,06 & 3 & 0,18 \\
\hline \multicolumn{5}{|c|}{ Kelemahan (Weaknesses) } \\
\hline 1 & $\begin{array}{l}\text { Kerja sama dengan bank untuk cicilan pembelian } \\
\text { masih minim. }\end{array}$ & 0,04 & 2 & 0,08 \\
\hline 2 & $\begin{array}{l}\begin{array}{l}\text { Terkadang terjadi telat pengiriman yang } \\
\text { disebabkan oleh beberapa hal. }\end{array} \\
\end{array}$ & 0,05 & 2 & 0,10 \\
\hline 3 & $\begin{array}{l}\text { Tidak ada web application agar bisa melakukan } \\
\text { pembelian secara online. }\end{array}$ & 0,08 & 1 & 0,08 \\
\hline 4 & $\begin{array}{l}\text { Adanya peluang untuk masuknya barang } \\
\text { subtitusi dengan harga yang lebih murah hanya } \\
\text { saja kualitasnya berbeda. }\end{array}$ & 0,08 & 1 & 0,08 \\
\hline 5 & $\begin{array}{l}\text { Harga produk yang dijual PT Fondaco memang } \\
\text { lebih tinggi dibandingkan dengan pesaing. }\end{array}$ & 0,12 & 1 & 0,12 \\
\hline 6 & $\begin{array}{l}\text { Kurangnya SDM untuk tim edukasi yang telah } \\
\text { ada. }\end{array}$ & 0,06 & 2 & 0,12 \\
\hline 7 & $\begin{array}{l}\text { Untuk karyawan baru, kurang diadakan pelatihan } \\
\text { dan training tentang produk yang ada. }\end{array}$ & 0,07 & 2 & 0,14 \\
\hline & Total & 1,00 & & 2,58 \\
\hline
\end{tabular}

Hasil :

Total perkalian antara bobot dengan peringkat yang menunjukkan angka 2.58 dapat diartikan bahwa internal manajemen PT Fondaco Jayatama cukup kuat. Walaupun 
adanya kelemahan-kelemahan, perusahaan harus terus melakukan berbagai macam perbaikan dan mengembangkan kekuatan yang dimiliki.

Matrix IE

\section{- Matching Stage}

Gabungan dari EFE dan IFE matriks, menghasilkan IE Matriks yang dapat menentukan posisi perusahaan. Berikut matriks gabungan nya :

\section{Matriks Internal-Eksternal PT Fondaco Jayatama}

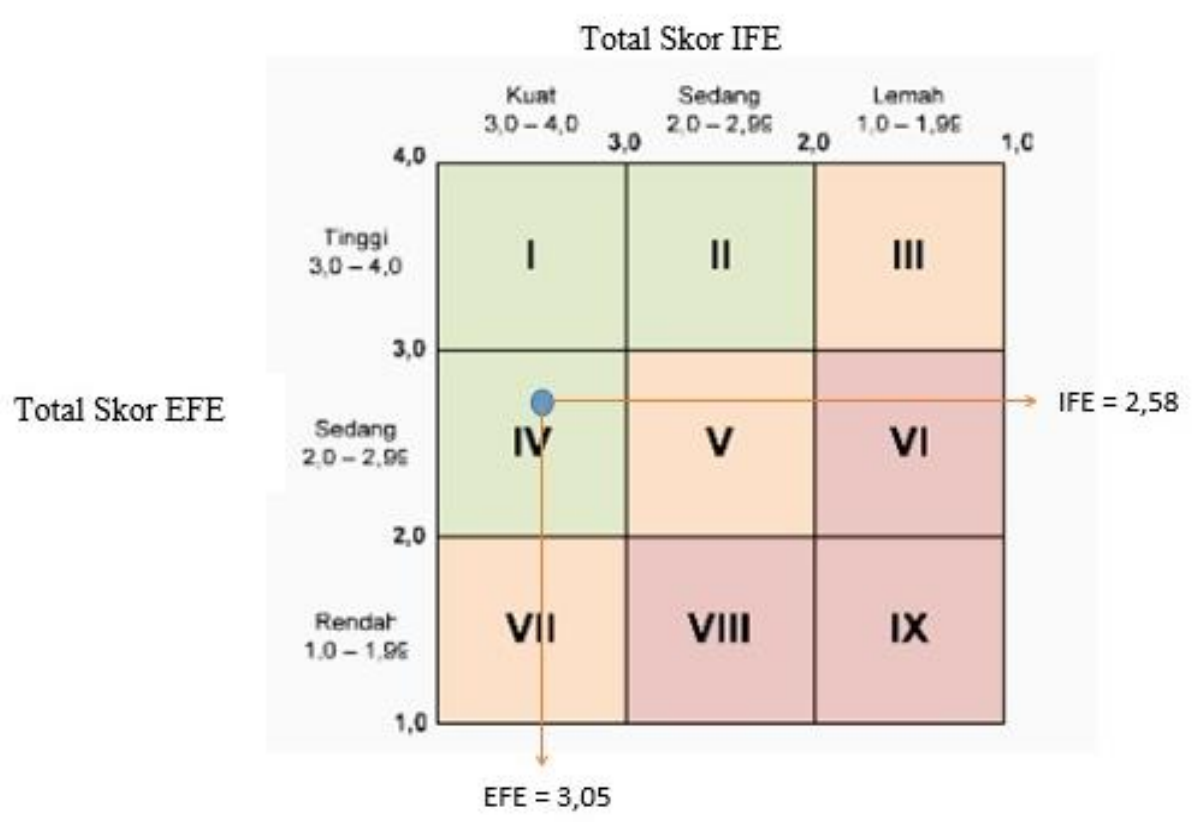

IE Matriks diataas menunjukan bahwa PT Fondaco Jayatama berada di kuadran IV, dengan nilai EFE 3.05 dan IFE 2,58 yang berarti PT Fondaco Jayatama berada dalam posisi Grow and Build. Strategi yang dapat diterapkan dan cocok untuk dilakukan adalah strategi intensif (yaitu dengan melakukan penetrasi pasar, pengembangan pasar, dan juga pengembangan produk). Hal ini akan menjadi dasar bagi penulis dalam mendapatkan strategi yang tepat pada analisis selanjutnya.

- Berdasarkan data matriks yang ada, maka dapat disimpulkan, bahwa dapat dilihat matriks IE merekomendasikan strategi pentrasi pasar, pengembangan pasar, dan pengembangkan produk. Matriks SWOT lebih mengacu pada pentrasi pasar dan pengembangan produk, sedangkan untuk matriks grand strategy merekomendasikan pentrasi pasar, pengembangan produk, dan pengembangan pasar. Dapat dilihat bahwa strategi yang terdapat pada ketiga matriks penentuan strategi adalah penetrasi pasar dan pengembangan produk. Maka kedua strategi ini akan diuji kembali pada Quantitative Strategic Planning Matrix (QSPM).

\begin{tabular}{|c|c|c|c|}
\hline Strategi & $\begin{array}{c}\text { Matriks } \\
\text { IE }\end{array}$ & $\begin{array}{c}\text { Matriks } \\
\text { SWOT }\end{array}$ & $\begin{array}{c}\text { Matriks Grand } \\
\text { Strategy }\end{array}$ \\
\cline { 2 - 4 } & $\mathbf{X}$ & $\mathbf{X}$ & $\mathbf{X}$ \\
\hline $\begin{array}{c}\text { Pentrasi Pasar } \\
\text { Pasar }\end{array}$ & $\mathbf{X}$ & & $\mathbf{X}$ \\
\hline $\begin{array}{c}\text { Pengembangan } \\
\text { Produk }\end{array}$ & $\mathbf{X}$ & $\mathbf{X}$ & $\mathbf{X}$ \\
\hline
\end{tabular}




\section{- Decision Stage}

- Quantitative Strategic Planning Matrix (QSPM)

Matriks QSPM digunakan untuk mengevaluasi strategi alternatif berdasarkan attractiveness score secara objektif yang dilihat berdasarkan faktor-faktor internal dan faktor-faktor eksternal perusahaan. Setelah melakukan pencocokan dari berbagai matriks (InternalEksternal, SWOT, dan Grand Strategy), Strategi yang dianalisis adalah penetrasi pasar dan pengembangan produk. Berikut adalah tabel QSPM PT Fondaco Jayatama.

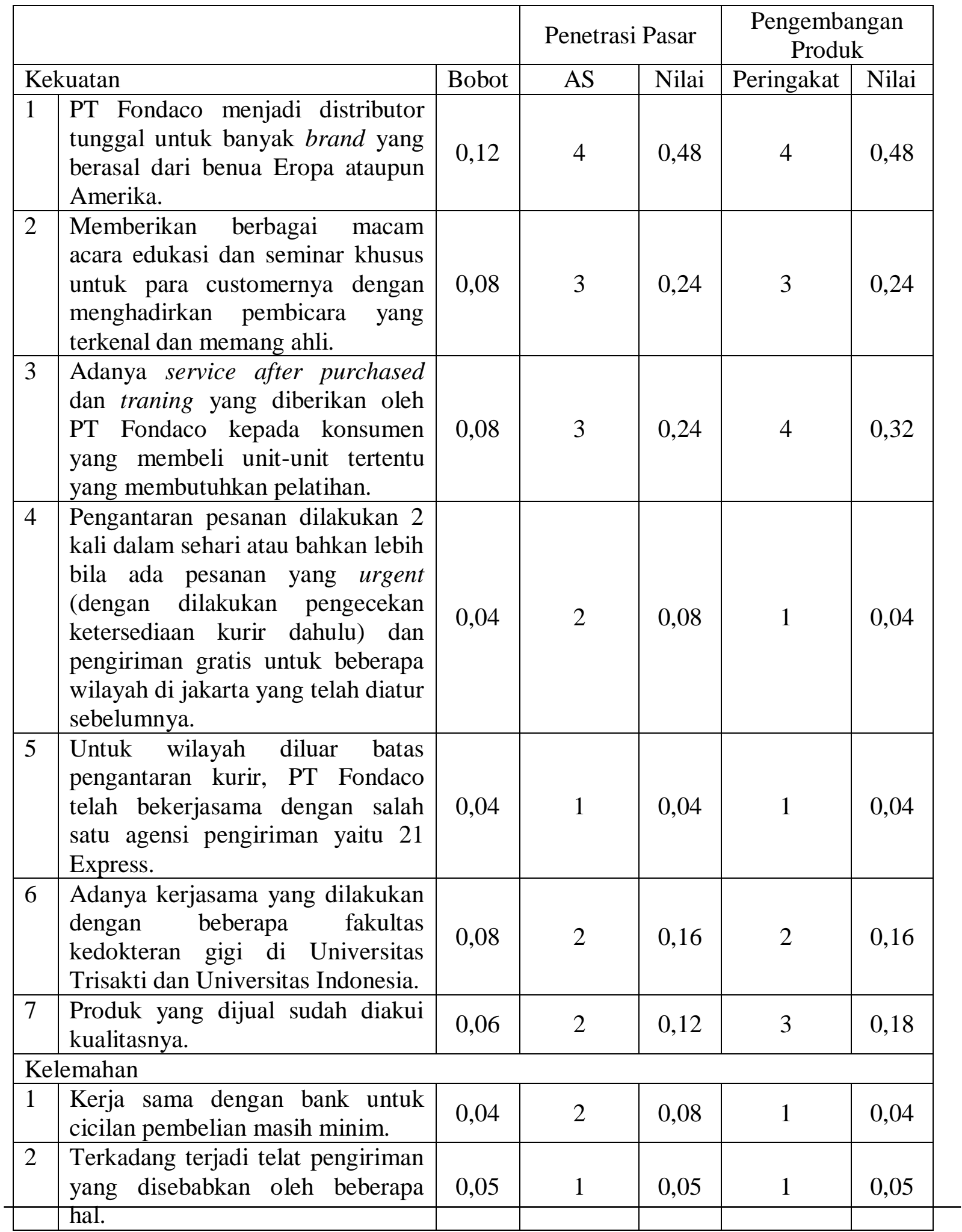




\begin{tabular}{|c|c|c|c|c|c|c|}
\hline 3 & $\begin{array}{l}\text { Tidak ada web application agar } \\
\text { bisa melakukan pembelian secara } \\
\text { online. }\end{array}$ & 0,08 & 1 & 0,08 & 2 & 0,16 \\
\hline 4 & $\begin{array}{l}\text { Adanya peluang untuk masuknya } \\
\text { barang subtitusi dengan harga } \\
\text { yang lebih murah hanya saja } \\
\text { kualitasnya berbeda. }\end{array}$ & 0,08 & 3 & 0,24 & 4 & 0,32 \\
\hline 5 & $\begin{array}{l}\text { Harga produk yang dijual PT } \\
\text { Fondaco memang lebih tinggi } \\
\text { dibandingkan dengan pesaing. }\end{array}$ & 0,12 & 3 & 0,36 & 2 & 0,24 \\
\hline 6 & $\begin{array}{l}\text { Kurangnya SDM untuk tim } \\
\text { edukasi yang telah ada. }\end{array}$ & 0,06 & 2 & 0,12 & 1 & 0,06 \\
\hline 7 & $\begin{array}{l}\text { Untuk karyawan baru, kurang } \\
\text { diadakan pelatihan dan training } \\
\text { tentang produk yang ada. }\end{array}$ & 0,07 & 2 & 0,14 & 2 & 0,14 \\
\hline & Total & 1,00 & & & & \\
\hline \multicolumn{7}{|c|}{ Peluang } \\
\hline 1 & $\begin{array}{l}\text { Market size yang besar, } \\
\text { menjangkau seluruh Indonesia }\end{array}$ & 0,16 & 2 & 0,32 & 2 & 0,32 \\
\hline 2 & $\begin{array}{l}\text { Mulai adanya kesadaran dari } \\
\text { konsumen bahwa kualitas yang } \\
\text { baik itu penting. }\end{array}$ & 0,05 & 2 & 0,10 & 3 & 0,10 \\
\hline 3 & $\begin{array}{l}\text { Adanya pertumbuhan ekonomi } \\
\text { masyarakat Indonesia. }\end{array}$ & 0,08 & 2 & 0,16 & 2 & 0,16 \\
\hline 4 & $\begin{array}{l}\text { Pesaing di industri yang sama } \\
\text { masih terbilang sedikit. }\end{array}$ & 0,07 & 3 & 0,21 & 2 & 0,14 \\
\hline 5 & $\begin{array}{l}\text { Adanya keunggulan karena sudah } \\
\text { dikenal bahkan sampai ke luar } \\
\text { negri, sehingga mudah untuk } \\
\text { memanggil pembicara yang } \\
\text { berasal dari luar Indonesia. }\end{array}$ & 0,09 & 3 & 0,27 & 2 & 0,18 \\
\hline \multicolumn{7}{|c|}{ Ancaman } \\
\hline 1 & $\begin{array}{l}\text { Adanya pesaing yang menjual } \\
\text { produk yang sama dengan harga } \\
\text { yang lebih murah. }\end{array}$ & 0,16 & 2 & 0,32 & 2 & 0,32 \\
\hline 2 & $\begin{array}{l}\text { Terjadi persaingan harga yang } \\
\text { ketat. }\end{array}$ & 0,16 & 2 & 0,32 & 2 & 0,32 \\
\hline 3 & $\begin{array}{l}\text { Produk yang dijual termasuk untuk } \\
\text { kalangan menengah keatas. }\end{array}$ & 0,08 & 3 & 0,24 & 4 & 0,32 \\
\hline 4 & $\begin{array}{l}\text { Kurangnya kesadaran } \text { dari } \\
\text { konsumen bahwa lebih nyaman } \\
\text { untuk menggunakan produk } \\
\text { dengan kualitas yang baik. }\end{array}$ & 0,05 & 2 & 0,10 & 3 & 0,15 \\
\hline 5 & $\begin{array}{l}\text { Ada beberapa calon pembeli yang } \\
\text { sudah terdoktrin bahwa yang dijual } \\
\text { oleh PT Fondaco terlampau mahal. }\end{array}$ & 0,10 & 2 & 0,20 & 3 & 0,30 \\
\hline \multicolumn{2}{|c|}{ Total } & 1,00 & & & & \\
\hline
\end{tabular}




\begin{tabular}{|l|l|l|l|l|l|}
\hline Total Attractive Score & & & 4,67 & & 4,78 \\
\hline
\end{tabular}

\section{KESIMPULAN DAN SARAN \\ Kesimpulan}

Beberapa kesimpulan mengenai strategi yang akan digunakan dalam rangka meningkatkan persaingan, yakni :

1. PT Fondaco Jayatama dapat berkonsentrasi untuk menggunakan strategi pengembangan produk.

2. Kekuatan yang dimiliki perusahaan adalah produk yang dijual beragam, bermerk, dan memiliki kualitas yang lebih baik dibandingkan dengan pesaing.

3. Adanya persaingan harga yang ketat, karena harga produk PT Fondaco Jayatama terbilang untuk kalangan menengah keatas. Namun hal tersebut bisa disiasati dengan mengadakan promo-promo menarik.

4. Adanya ancaman untuk masuknya pesaing baru karena untuk industri ini masih terbilang sedikit jumlahnya.

5. Service after purchased yang diberikan juga menambah nilai kepuasan pelanggan.

6. PT Fondaco Jayatama juga telah memiliki kerjasama dengan beberapa fakultas Saran kedokteran gigi di beberapa universitas ternama di Jakarta

Berdasarkan dari penelitian yang telah dilakukan, terdapat beberapa rekomendasi strategi sebagai masukan dan bahan pertimbangan bagi PT Fondaco Jayatama untuk bersaing, yakni:

1. Perusahaan harus meningkatkan kesadaran atas merek di mata publik, karena masih ada beberapa konsumen yang mungkin tidak memperhatikan merk dari produk yang dibeli yang sebenarnya dari merk tersebut akan mencermintan kualitas produk tersebut sehingga hanya mencari harga yang rendah merupakan prioritas mereka.

2. Meningkatkan partisipasi dalam mengikuti berbagai event baik sebagai sponsor atau juga peserta untuk dapat membantu meningkatkan awareness konsumen.

3. Memperkenalkan produk baru yang dikembangkan dengan memberikan promo dan bekerja sama dengan fakultas kedokteran gigi.

4. Mentraining para karyawannya, karena respon dan pelayanan terhadap pelanggan sangat penting.

\section{DAFTAR PUSTAKA}

Dagmino, Giovanni B. (2012). Handbook of Research on Competitive Strategy. Cheltentam: Edward Elgar Publishing Limited.

David, Fred R. (2011). Strategic Management Concepts and Cases, Thirteenth Edition. New Jersey: Prentice Hall.

Grant, Robert M. (2016). Contemporary Strategy Analysis, $9^{\text {th }}$ Edition. Chicester: Wiley \& Sons Ltd.

Huggins, Robert \& Izushi, Hiro. (2011). Competition, Competitive Advantage, and Clusters: The Ideas of Michael Porter. New York: Oxford University Press Inc.

Neuman, W Lawrence. (2003). Social Research Methods: Qualitative and Quantitative Approaches, $5^{\text {th }}$ edition. Boston: Pearson Education Inc.

Pearce, J. A., \& Robinson, R. B. 1. (2013). Strategic management: Planning for domestic \& global competition, $13^{\text {th }}$ ed. New York: McGraw-Hill/Irwin.

Porter, Michael E. "The Five Competitive Forces That Shape Strategy". Special Issue On HBS Centennial. Harvard Business Review 86, no. 1 (January 2008): 78-93.

Rogers, Stephen C. (2009). The Supply-Based Advantage: How to Link Suppliers to Your Oraganization's Coorporate Strategy. New York: Amacom. 
Scott, D. L. (2010). American Heritage Dictionary of Business Term. Boston: Houghton Mifflin.

Thompson Jr., Arthur A., Peteraf, Margaret A., Gamble, John E., \& Strickland III, A. J. (2012). Crafting and Executing Strategy: The Quest for Competitive Advantage: Concepts and Cases, $18^{\text {th }}$ Edition. New York: McGraw-Hill/Irwin.

Wheelen, T. L. \& Hunger, J. D. (2012). Strategic Management and Business Policy:Achieving Sustainability, $13^{\text {th }}$ edition. New Jersey: Prentice Hall.

https://ekonomi.kompas.com/read/2018/05/07/184702226/analis-pertumbuhan-ekonomikuartal-i2018-di-bawah-ekspetasi 


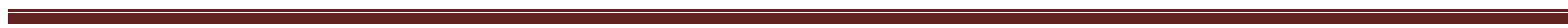
$\cdot$ 